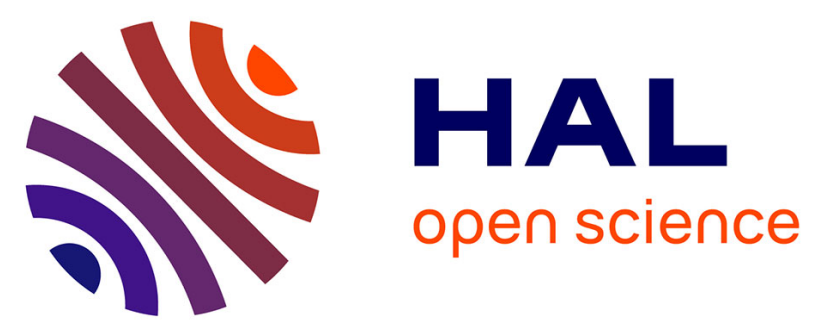

\title{
Exploring Open Data State-of-the-Art: A Review of the Social, Economic and Political Impacts
}

\author{
Shefali Virkar, Gabriela Viale Pereira
}

\section{To cite this version:}

Shefali Virkar, Gabriela Viale Pereira. Exploring Open Data State-of-the-Art: A Review of the Social, Economic and Political Impacts. 17th International Conference on Electronic Government (EGOV), Sep 2018, Krems, Austria. pp.196-207, 10.1007/978-3-319-98690-6_17 . hal-01961530

\section{HAL Id: hal-01961530 \\ https://hal.inria.fr/hal-01961530}

Submitted on 20 Dec 2018

HAL is a multi-disciplinary open access archive for the deposit and dissemination of scientific research documents, whether they are published or not. The documents may come from teaching and research institutions in France or abroad, or from public or private research centers.
L'archive ouverte pluridisciplinaire HAL, est destinée au dépôt et à la diffusion de documents scientifiques de niveau recherche, publiés ou non, émanant des établissements d'enseignement et de recherche français ou étrangers, des laboratoires publics ou privés.

\section{(c)(1)}

Distributed under a Creative Commons Attribution| 4.0 International License 


\title{
Exploring Open Data State-of-the-Art: A Review of the Social, Economic and Political Impacts
}

\author{
Shefali Virkar ${ }^{1}$ and Gabriela Viale Pereira ${ }^{1}$ \\ ${ }^{1}$ Danube University Krems, 3500 Krems, Austria \\ \{shefali.virkar,gabriela.viale-pereira\}@donau-uni.ac.at
}

\begin{abstract}
This research paper explores the impact that the access to, and free usage of, stored (mainly public sector) data has on society, the economy and on good governance, together with the implications of this new paradigm for modern-day governments. Although a number of recent research studies attempt to identify the benefits and drawbacks of open data, or to demonstrate its role in governance processes, there exists to-date no systematic attempt to both rigorously survey current literature to enumerate the areas in which open data has had an impact and to discuss its potential as a significant tool for policymaking. To address this research gap, and to highlight its intrinsic value to different actors, we examine the current state-of-the-art on the impacts of open data research and practice through a systematic survey of extant scholarly and practitioner literature. The first part of our study will present a comprehensive overview of the societal, economic, and political impacts of open data. We will then evaluate the new possibilities afforded by open data to policymaking, and conclude with a discussion of its role in open governance.
\end{abstract}

Keywords: Open data, open government data, effects of open data.

\section{Introduction}

As digital technologies come to be applied in different domains and sectors, most especially in the public sector, new possibilities for innovating governance have been created by the growth in data, computational power and social media [1]; all of which signal a new Era that is data-driven. In this scenario, open data emerges, being "one step further the knowledge-based society and economy" [2].

Open Government Data (OGD) can be considered as a specific subset of data which lies on the open data and government data domains [3]. Open Government has OGD as one of its principles, but requires also an extensive transformation of the public sector and its relationship with the public that needs to be mediated by information and communication technology (ICT) [4]. The principles of open government are data openness, transparency, participation, and collaboration [5]. Based on these principles, the idea of open government is to establish a modern cooperation among politicians, public administration, industry and private citizens [6].

In order to highlight the value of open data, the objective of this study is to present a comprehensive overview from the academic literature and practice on the impacts of open data along the following dimensions: 1) Social Impacts, 2) Economic impacts, 
and 3) Impact on Good Governance. The section on the creation of social capital covers the influence that the opening of data has on society and the rights of the individual. For instance, citizen empowerment and democracy are identified as core expected effects of OGD initiatives [7]. The second topic, economic impact, is often measured in monetary terms and the generation of revenue. For example, when analysing the effects of OGD utilization [8], economic development is considered the second most prominent aspect. Within the third domain, the role played by open data in the furtherance of good governance is discussed. Here transparency and accountability are listed amongst the primary effects of OGD initiatives [8].

The main theoretical contribution of this study pertains to the provision of an overview of the current state-of-the-art in open data research as one of the first comprehensive reviews to have a focus on the various impacts of OGD. The practical implications affect policymakers and governmental institutions by providing recommendations on how to maximize the benefits of OGD implementation, especially but not limited to any specific national context.

This paper starts by presenting a review of open data state-of-the-art and the methodology applied to this study. The research design is followed by the results and analysis of the literature review. The following section then presents policy recommendations. Finally, concluding remarks and an agenda for future research are discussed.

\section{A Review of Open Data State-of-the-Art}

Despite the clear potential of data for innovation $[9,10]$ and the growing amount of data that have been opened by several levels of government around the world, there are still doubts as to whether OGD will achieve all the expected benefits [11]. Open data has become a topic of increasing importance in research and practice, with a particular expansion in recent years $[8,12]$. Despite being investigated with greater focus on public sector settings, open data studies are not exclusively related to government but also conducted in private settings [2]. "The foundation of the information provided by the government is referred to as open data, sets of data published by government that can be read and interpreted by either humans or machines" [13]. This study pays particular attention to data opened by governmental organizations, but we use the terms OGD and open data interchangeably for convenience.

The main impacts of open data initiatives in local governments are related to the use of data to improve decision-making and to better meet the needs of citizens (user side), as well as promoting transparency (provider side), due to the fact that governments provide access to and stimulate the re-use of public sector information [2,14]. Transparency was also identified by [15] as one of the main objectives of opening government data, together with the direct impact provided by information access, increase in accountability and new possibilities for citizens to participate in the governance process.

Three recent literature reviews explore the OGD topic; focusing on the utilization of OGD [8], on assessing OGD initiatives [15] and providing insights from open data research [2]. Although the first two provide some discussion about the impact of OGD on stakeholders and main effects of OGD utilization, an overview of the current state-of- 
the-art in open data and its impact is lacking. The same applies to benchmarking studies such as the Global Open Data Index (GODI) ${ }^{1}$ that focus on open government data publication from a civic perspective, but do not look at other aspects such as context, use or impact.

Proponents of OGD believe that the new role of the public sector as an information provider will have an impact on the creation of social and economic value and on the attainment of good governance [8]. Cultural challenges of open government data initiatives have strong relation to awareness about the benefits and potential of open data [15].

\section{$3 \quad$ Methodology}

In order to analyse the existing knowledge on the impacts of open government data we conducted a systematic literature review as recommended by [16], based on the framework proposed by [17]. According to [16], a systematic literature review involves “...identifying, evaluating and interpreting all available research relevant to a particular research question, or topic area, or phenomenon of interest." In agreement with [16], we adopted a pre-defined search strategy to ensure that our literature review was thorough, fair, and of robust scientific value. Following [17], the design of the review for this paper consisted of: defining the search terms; selecting the sources; applying the search in the sources; going backward by reviewing the citations for the articles, selecting the sample based on the abstracts and finally based on the full-text.

The Scopus database (a comprehensive, reputable database for peer-reviewed scholarly and practitioner literature) and the Government Information Quarterly Journal (recognized as one of the main sources of literature in the government community) were selected as the main sources for the systematic literature review. Conventional key word searches using the search terms "open data" (6,407 articles) and "open government data" (481 articles) were conducted as the first step. Refinement of these results by publication date (only recently published articles from 2010 to the present), and subject relevance (proximity of abstract to topic based on author judgement) yielded 537 papers. The second round of refinement included looking for terms such as "impact", "effects", "implications" within the title, abstract, or keywords of this list for identifying specific aspects of open data. This step resulted in the identification of 80 papers. Finally, based on the citations from the identified articles in the first and second steps we determined further material that was also relevant for the analysis. The findings of the 60 most pertinent articles are summarised and discussed here.

\section{$4 \quad$ Findings on the impacts of open data}

One of the primary objectives of this research paper is to delineate and discuss in adequate detail the different domains within which open data bears significant effect so as

\footnotetext{
${ }^{1}$ https://index.okfn.org/methodology/
} 
to construct the foundation of a policy roadmap for the future release of information and knowledge. As discussed previously, a list of impacts pertaining to open data have been extracted through a systematic literature analysis of indexed scientific works, and are presented to the reader in this chapter. Our research findings are organized in the following manner: The first section is concerned with the social and political implications of open data. The second section deals with open data's economic implications. The third section outlines the contribution made by open data to good governance. Each derived proposition is then classified as one or the other, and listed, and then discussed.

\subsection{Generating Social Value through Open Data}

Innovation in Public Services: Open data can foster innovation in public service provision [18], wherein the act of making information widely available increases the participation of a range of non-institutional actors who co-create [19] and renew public services [18] alongside the government. Considering that opening public data can result in improved public service standards, the provision of open data significantly changes the roles played by government [20] and citizens [21] in the production and consumption of these services. However, information availability and accessibility alone are not sufficient conditions to leverage social value from open data $[19,22]$. Innovation in public services only arises through the re-use, dissemination and linking up of open government datasets [23]. The provision of tools and value-creation techniques must accompany any public release of data [19].

Fostering Citizen Empowerment: The release of open data contributes towards the empowerment of individuals within a society by altering the nature and scope of role that they play in the process of governance [24, 25, 26, 27, 28]. Citizen empowerment arises through a combination of access to open government data, and the availability of tools and technologies to combine it creatively. The provision of open data has altered the mindset of citizens towards government [24], actively engaging individuals in processes of governance [27]. Collaborative technologies and social software have further accelerated this change [28]. Thus, building an environment that encourages the emergence of networks of collaboration and co-creation, alongside the provision of open datasets, can translate into the empowerment of individuals within a society [26].

Promoting Meaningful Citizen Engagement: In providing the public with the data necessary to take well-informed decisions and actively engage with each other and with government, the release of open data has the potential to make citizen collaboration more meaningful $[29,30,31,32]$. Being able to regularly access high quality data about public services and government activities within an open data ecosystem will enable citizens to engage in meaningful dialogue with government $[30,32]$. The open data ethos, through the free-access provision of information and tools, encourages proactive citizen engagement by encouraging individuals to independently develop creative solutions to complex societal problems [32]. Government can guide these interactions, channeling efforts into priority areas, with active and regular public engagement in the co-creation of public services also being measured against the achievement of tangible societal and political outcomes [12]. 
Implications for Data Protection and Privacy: The opening up of government datasets for use by the general public has particularly significant ramifications for data protection and individual privacy [33, 34, 35, 36, 37]. While open data initiatives aim to create public value through (largely) unfettered innovation and transparent practices, increased openness may also lead to breaches in privacy and security violations as data potentially containing personally identifiable information (PII) is released into the public domain [33]. A balance needs to be struck between protecting the latter and leveraging the enormous potential benefit afforded by the public release of data $[34,36]$. To prevent privacy breaches, it is necessary to eliminate all privacysensitive attributes prior to the opening of data [37].

\subsection{Generating Economic Value through Open Data}

Encouraging Entrepreneurship: The relationship between open data and entrepreneurship is mutually reinforcing [38]; on the one hand, open data fosters entrepreneurship [39], whilst on the other, entrepreneurs create value out of open data [40]. The recognition that open data acts as a catalyst, enabler, and foundation for entrepreneurial activity has been recognized both in policy circles [41] and in academic scholarship [22, 39]. At the same time, the real economic value contribution from data comes from the business insights that are extracted from it [42]. Creative business insight falls to entrepreneurs who, in their quest to carve out niche markets and diversify revenue streams, find themselves best placed to bring together information and knowledge from different sources [40].

Promoting Innovation: Open data has been seen to have a significant positive impact on the creation of economic value by supporting increased rates of innovation $[43,44]$. The use of open data creates multiple business opportunities for companies: both established firms [44], as well as SMEs and entrepreneurs [39], can use open data in combination with new technologies and existing proprietary information to develop new products and services, improve existing offerings, and drive forms of innovative entrepreneurship that are at once commercially profitable and beneficial for the public good [22]. The full business potential of open data cannot, however, be harnessed if governments withhold access to particular datasets or privilege the release of certain types over others [45].

Impact on Economic Efficiency and Resource Allocation: The provision of open data by government and private organisations creates economic efficiency gains by enabling the better, more responsible allocation of existing resources and by minimizing resource wastage $[45,46]$. The provision of open data cuts data processing and transaction costs, facilitates strategic connections between economic entities, and empowers key actors [47]. Ready access to data can also reduce asymmetries of information [40].

Open Data Business Models: The widespread availability of data, and especially the increasing prevalence of open government data, has resulted, not only in the establishment of new companies, but in the emergence and adoption of new data-centric business models to drive product development, service provision and expansion into new markets [48, 49, 50]. These so-called 'Open Data Business Models' or ODBMs 
[49] place open data and associated tools at the heart of strategic decision-making and the development of goods and services, and are essential for firms wanting to leverage the economic potential of open data.

\subsection{Open Data for Promoting Good Governance}

Impact on Public Accountability: Open data can be a powerful enabler for public accountability, whereby the publishing of government data online in machine-readable and easily interpretable formats for consumption by citizens and firms effectively holds up government actions to general scrutiny $[51,52]$. Similarly, the shift towards the provision of big open data by government has made the imperative for public accountability even greater [53]. Open government portals need, therefore, be designed to fully support ordinary citizens engaged in public accountability efforts [54].

Impact on Transparency: The opening of data has profound implications for notions of public transparency $[55,56]$. Public transparency is one of the three principles around which the open government paradigm has been constructed, and a major objective of releasing open data for governments has become its promotion [53]. However, there is inconclusive evidence that the conscious opening of publicly held data will automatically lead to increased transparency [4]. Instead, progression from an open government to a transparent one is not considered altogether straightforward [56], as it is argued that the release of open data in machine-readable formats is seldom accompanied by the mechanisms necessary to facilitate its better understanding [55].

Creating Public Sector Efficiency Gains: Open data has the potential to modernize and streamline public sector operations; especially when used in combination with technology, and released in line with appropriate regulatory frameworks [57]. In fact, the improvement of operational efficiency is often listed as a compelling reason for governments to open their data to the public $[24,58]$. Further, the realization of public sector efficiency gains through the release of open data is sometimes considered a pre-condition for good governance [59].

Open Data and Civil Society Organisations: The release of open data has been seen to have a positive impact on the day-to-day operations of civil society organisations [40], and has the potential to transform the role that these actors play in the governance process [60]. Detailed information on the location of resources, and on the quality of existing systems, can both facilitate the resource mobilization activities performed by this sector [40] and support dialogue or collective deliberation with public officials [61]. Equipped with this knowledge, civil society organisations are also well placed to create awareness about open data and to identify those datasets which possess intrinsic social value [60]. However, it may be argued that while open datasets support civil society bodies, the interests of marginalised groups represented by these organisations may not be immediately served by the provision of machinereadable data online [61]. 


\section{Discussion: Insights and Implications for Policymaking}

In this section, we aim to propose some practical recommendations for open government data implementation. In general, open data is seen to play a significant role in the generation of social capital and creation of value within the economic context. Open data can also contribute to the advancement of good governance. These aspects imply that widespread access to data offers significant opportunities for policymakers to develop better-informed public policy, and can transform governance processes by encouraging participatory and collaborative decision-making. The maximization of the benefits accruing from open data in the move towards open governance and the provision of inputs for evidence-based policy making will be discussed below.

\subsection{Exploring the Implications of Open Data-driven Transformation}

Digital transformation is changing the process of policymaking and altering governance models in a disruptive way. Developments in open data, data processing, data mining and visualizations combined with social media, participatory tools and civic engagement are responsible for the changes in the policy-making field [1]. Our research has highlighted six pre-requisites for open data-driven transformation, mapped in Figure 1:

1. Technical: Facilitating user-friendly access to high quality machine-readable data.

2. Legal: Creation of an appropriate legal and regulatory framework for the release of open data.

3. Environmental: Fostering of a permissive culture that supports government-citizen collaboration, co-creation and, eventually, open innovation.

4. Institutional: Streamlining of government organisations to better engage with open data and convert basic information into public goods.

5. Economic: Adoption of data-centric business models for strategic decision making and product/service development.

6. Financial: Incentivisation of data-driven actions leading to innovation.

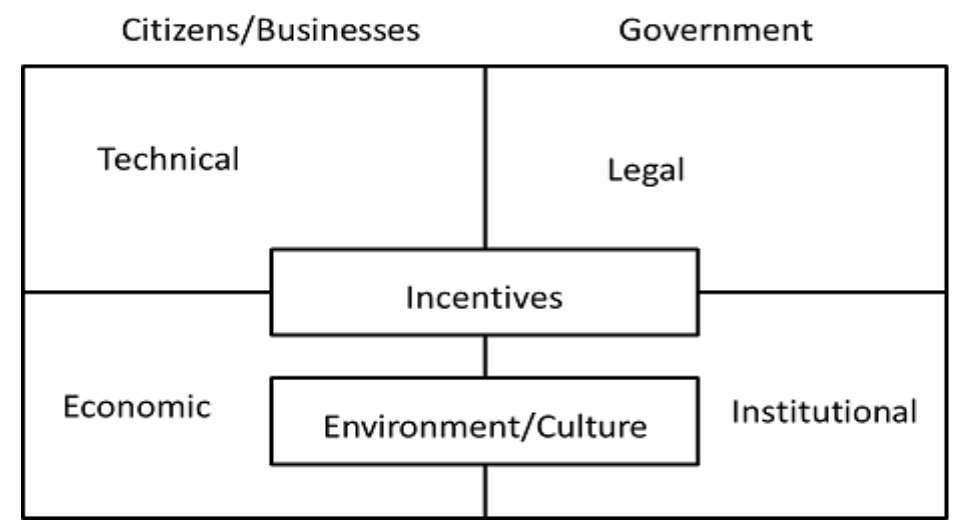

Availability of

Open Data

Usage of

Open Data

Fig. 1. Mapping Open Data-driven Transformation 
In order to maximize the benefits of open data in the move towards open governance, data needs to be open, the re-use of data should be facilitated to achieve social and economic value, interdisciplinary collaboration should be legitimized, as well as participation and engagement practices in decision making encouraged.

\subsection{Towards Open Governance}

Open governance is a concept that has emerged from the understanding that information belongs to the public, and, alongside with electronic democracy practices, can transform electronic government to electronic governance [62]. Open government is highly related to the collaborative governance concept, since open data increases the possibilities for knowledge development, decision making and interdisciplinary collaboration [63]. Citizens' willingness to engage is related to both their perception of government openness to integrate public opinion to formulate decisions and the amount of open public sector information to which they have access [13]. When analysing collaborative governance, [64] identified that information sharing and cooperation are the main elements framing the use of ICT to enable collaborative governance along with participation and engagement practices in decision making. In this sense, collaboration in government has as its main goal the enabling of stakeholders to participate in decision making processes that are efficient and effective [15].

\section{Conclusion}

The objective of this study was to explore the impact that the access to, and free usage of, stored (mainly public sector) data has on society, the economy, and on good governance. In order to achieve this aim, our research made use of a systematic review of current scholarship, and developed a framework that sets out the implications of this new paradigm for policymakers within modern-day governments. This study identified 12 key domains within which the use of open data had the potential to transform and generate social, political, and economic value. These domains were then used as the basis for the development of the foundations for policy recommendations in the field of open data; most particularly to highlight the contribution made by open data to transformations in government decision-making and policymaking.

The results of the literature review highlighted several key insights, pre-conditions for effective open data usage. The first of these is that open data has become a critical input for evidence-based policy-making, which can be achieved through new tools and technologies such as big data analytics. However, data needs to be not just available but accessible in formats that re-usable to generate social, political and economic value. Third, the opening up of data increases its re-use as it exposes information to a wider audience. However, data in circulation needs to be of a certain high quality, and needs to be accompanied by the right tools and technology for it to reach those who can actually make use of it. Fourth, there is a need to invest in technology and skills that will create value out of open data. Fifth, open data may be free but data analytics still requires an 
investment. Money, time and effort need to be spent to maintain and sustain open data portals. And finally, there is requirement to open data across the board whilst setting out strategic incentives to channel value generation to where it is needed.

In conclusion, it is vital that not only is data available and easily accessible to the public, but also that the appropriate tools and regulatory frameworks are put in place to ensure that the use and re-use of open data is meaningful.

\section{References}

1. Janssen, M., Wimmer, M. A.: Introduction to Policy-Making in the Digital Age. In: Janssen, M., Wimmer, M.A., Deljoo, A. (eds.) Policy Practice and Digital Science - Integrating Complex Systems, Social Simulation and Public Administration in Policy Research, pp. 1-14. Springer International Publishing, Heidelberg (2015).

2. Hossain, M. A., Dwivedi, Y. K., Rana, N. P.: State-of-the-art in open data research: Insights from existing literature and a research agenda. Journal of organizational computing and electronic commerce 26(1-2), 14-40 (2016).

3. Kučera, J., Chlapek, D., Nečaský, M.: Open government data catalogs: Current approaches and quality perspective. In: Ko, A., Leitner, C., Leitold, H., Prosser, A. (eds.)TechnologyEnabled Innovation for Democracy, Government and Governance - International Conference on Electronic Government and the Information Systems Perspective, pp. 152-166. Springer, Berlin, Heidelberg (2013).

4. Janssen, M., Matheus, R., Longo, J., Weerakkody, V. Transparency-by-design as a foundation for open government. Transforming Government: People, Process and Policy 11(1), 2 8 (2017).

5. Veljković, N., Bogdanović-Dinić, S., Stoimenov, L.: Benchmarking open government: An open data perspective. Government Information Quarterly 31(2), 278-290 (2014).

6. Bauer, F., Kaltenböck, M.: Linked Open Data: The Essentials. Edition mono/monochrom, Vienna (2011).

7. Ruijer, E., Grimmelikhuijsen, S., Meijer, A.: Open data for democracy: Developing a theoretical framework for open data use. Government Information Quarterly 34(1), 45-52 (2017).

8. Safarov, I., Meijer, A., \& Grimmelikhuijsen, S.: Utilization of open government data: A systematic literature review of types, conditions, effects and users. Information Polity 22(1), 1-24 (2017).

9. OECD: Emerging issues: The Internet of Things. In OECD Digital Economy Outlook 2015, OECD Publishing, Paris (2015).

10. Zuiderwijk, A., Janssen, M., Davis, C.: Innovation with open data: Essential elements of open data ecosystems. Information Polity 19(1/2), 17-33 (2014).

11. Danneels, L., Viaene, S., Van den Bergh, J.: Open data platforms: Discussing alternative knowledge epistemologies. Government Information Quarterly 34(3), 365-378 (2017).

12. Gonzalez-Zapata, F., Heeks, R.: The multiple meanings of open government data: Understanding different stakeholders and their perspectives. Government Information Quarterly 32(4), 441-452 (2015).

13. Mellouli, S., Luna-Reyes, L. F., Zhang, J.: Smart government, citizen participation and open data. Information Polity 19(1,2), 1-4 (2014).

14. Viale Pereira, G., Cunha, M. A., Lampoltshammer, T. J., Parycek, P., Testa, M. G.: Increasing collaboration and participation in smart city governance: a cross-case analysis of smart city initiatives. Information Technology for Development 23(2), 1-28 (2017). 
15. Attard, J., Orlandi, F., Scerri, S., Auer, S.: A systematic review of open government data initiatives. Government Information Quarterly 32(4), 399-418 (2015).

16. Kitchenham, B.: Procedures for Performing Systematic Reviews. Joint Technical Report Keele University Technical Report TR/SE-0401\& NICTA Technical Report 0400011T.1, June 2004 (2004).

17. Webster, J., Watson, R.T.: Analyzing the Past to Prepare for the Future: Writing a Literature Review, MIS Quarterly 26(2), pp. XIII-XXIII (2002).

18. OECD: Rebooting Public Service Delivery: How Can Open Government Data Help to Drive Innovation? An OECD Comparative Study. (2017). http://www.oecd.org/gov/Rebooting-Public-Service-Delivery-How-can-OpenGovernment-Data-help-to-drive-Innovation.pdf, last accessed 2017/09/15.

19. Attard, J., Orlandi, F., Auer, S.: Data driven governments: creating value through open government data. In: Hameurlain, A., Kung, J., Wagner, R., Anjomshoaa, A., Hung, P.C.K., Kalisch, D. (eds.)Transactions on Large-Scale Data-and Knowledge-Centered Systems XXVII - Special Issue on Big Data for Complex Urban Systems, pp. 84-110. Springer, Berlin Heidelberg (2016).

20. Daglio, M., Gerson D., Kitchen H.: Building Organisational Capacity for Public Sector Innovation. Background Paper prepared for the OECD Conference "Innovating the Public Sector: from Ideas to Impact”, Paris, 12-13 November 2014 (2015).

21. Linders, D., Copeland Wilson, S., Bertot, J.C.: Open government as a vehicle for government transformation. In: Weerakoddy, V., Reddick, C.G. (eds.) Public Sector Transformation through E-Government: Experiences from Europe and North America, pp. 9-23. Routledge Press, New York, N.Y.(2012).

22. Jetzek, T., Avital, M., Bjorn-Andersen, N.: Data-driven innovation through open government data. Journal of Theoretical and Applied Electronic Commerce Research 9(2), 100120 (2014).

23. Chan, C.M.L: From open data to open innovation strategies: Creating e-Services Using Open Government Data. In: 2013 46th Hawaii International Conference on SSystem Sciences (HICSS) Proceedings (pp. 1890-1899). IEEE Press. (2013)

24. Weerakkody V., Irani Z., Kapoor K., Sivarajah U., Dwivedi Y.K.: Open data and its usability: an empirical view from the Citizen's perspective. Information Systems Frontiers 19(2), 285-300 (2017).

25. Ruijer E., Grimmelikhuijsen S., Hogan, M., Enzerink, S., Ojo, A., Meijer A.: Connecting societal issues, users and data. Scenario-based design of open data platforms. Government Information Quarterly 34(3), 470-480 (2017).

26. Craveiro G.S., Machado J.A.S., Machado J.S.: The use of open government data to citizen empowerment. In: ICEGOV '15-16 Proceedings of the 9th International Conference on Theory and Practice of Electronic Governance, pp. 398-399. ACM Press, New York, N.Y. (2016).

27. Geiger, C. P., Von Lucke, J.: Open government and (linked)(open)(government)(data). JeDEM-eJournal of eDemocracy and open Government 4(2), 265-278 (2012).

28. Maier-Rabler U., Huber, S.: "Open": the changing relation between citizens, public administration, and political authority. JeDEM-eJournal of eDemocracy and open Government 3(2), 182-191 (2011).

29. Johansson, D., Lassinantti, J., Wiberg, M.: Mobile e-services and open data in egovernment processes: transforming citizen involvement. In Proceedings of the 17th International Conference on Information Integration and Web-based Applications \& Services (iiWAS '15), Article No.8. ACM, New York (2015). 
30. Zuiderwijk, A., Janssen, M. Open data policies, their implementation and impact: A framework for comparison. Government Information Quarterly 31(1), 17-29 (2014).

31. Conradie, P., Choenni, S.: On the barriers for local government releasing open data. Government Information Quarterly 31(Supplement 1), S10-S17 (2014).

32. Kassen, M.: A promising phenomenon of open data: A case study of the Chicago open data project. Government Information Quarterly 30(4), 508-513, (2013).

33. Hardy, K., Maurushat, A.: Opening up government data for Big Data analysis and public benefit. Computer Law and Security Review 33(1), 30-37 (2017).

34. van Zoonen, L.: Privacy concerns in smart cities. Government Information Quarterly 33(3), 472-280 (2016).

35. Scassa, T.: Privacy and Open Government. Future Internet 6(2), 397-413 (2014).

36. Floridi, L.: Open data, data protection, and group privacy. Philosophy \& Technology 27(1), 1-3 (2014)

37. Meijer, R., Choenni, S., Alibaks, R. S., Conradie, P.: Bridging the contradictions of open data. In: Castelnovo, W., Ferrari, E. (eds.) Proceedings of the 13th European Conference on E-government, pp. 329-336. Academic Conferences and Publishing International Limited, Reading, UK (2013).

38. Walker, J., Simperl, E.: Analytical Report No. 10: Open Data and Entrepreneurship. Report for the European Data Portal. https://www.europeandataportal.eu/sites/default/files/analytical_report_10_open_data_and _entrepreneurship.pdf, last accessed 2018/03/07

39. Lakomaa, E., Kallberg, J.: Open data as a Foundation for Innovation: The Enabling Effect of Free Public Sector Information for Entrepreneurs. IEEE Access (2013), 558-563 (2013).

40. Manyika, J., Chui, M., Groves, P., Farrell, D., Van Kuiken, S., Doshi, E. A.: Open data: Unlocking innovation and performance with liquid information. Report by the McKinsey Global Institute, the McKinsey Centre for Government, and the McKinsey Business Technology Office, October 2013 (2013).

41. Meyer, E.: The Impact of Open Data. The White House - Blog, 08 April 2014. (2014) https://obamawhitehouse.archives.gov/blog/2014/04/08/impact-open-data, last accessed 2017/09/20.

42. Kamal, I.: Metrics are Easy: Insight is Hard. Harvard Business Review, 24 September 2012. (2012). https://hbr.org/2012/09/metrics-are-easy-insights-are-hard, last accessed 2017/09/20.

43. Susha I., Grönlund A., Janssen M.: Driving factors of service innovation using open government data: An exploratory study of entrepreneurs in two countries. Information Polity 20(1), 19-34 (2015).

44. Zimmermann H.-D., Pucihar, A.: Open Innovation, Open Data and New Business Models (September 1, 2015). (2015) https://ssrn.com/abstract=2660692, last accessed 2017/09/21

45. Carrara, W., Chan, W.S., Fischer, S., van Steenbergen, E.: Creating Value through Open Data. Study prepared as part of the European Data Portal (2015).

46. European Data Portal: Benefits of Open Data. (2017). https://www.europeandataportal.eu/en/using-data/benefits-of-open-data, last accessed 2017/09/21.

47. Berends, J., Carrara, W., Radu, C.: Analytical Report No. 9: The Economic Benefits of Open Data. Report for the European Data Portal. https://www.europeandataportal.eu/sites/default/files/analytical_report_n9_economic_bene fits_of_open_data.pdf, last accessed 2018/03/07

48. Koski, H.: The Impact of Open Data: A Preliminary Study. Ministry of Finance publications 15b/2015, March 2015. Government of Finland (2015). 
49. Zeleti F. A., Ojo A., Curry E.: Exploring the economic value of open government data. Government Information Quarterly 33(3), 535-551 (2016).

50. Bonina, C. M.: New business models and the value of open data: Definitions, challenges and opportunities, New Economic Models in the Digital Economy, London, UK (2013).

51. Misuraca G., Viscusi G.: Is open data enough? E-governance challenges for open government. International Journal of Electronic Government Research 10(1), 18-34 (2014).

52. Guéret, C., de Boer, V., Schlobach, S.: Let's" Downscale" Linked Data. IEEE Internet Computing 18(2), 70-73 (2014).

53. Sivarajah U., Weerakkody V., Waller P., Lee H., Irani Z., Choi Y., Morgan R., Glikman Y.: The role of e-participation and open data in evidence-based policy decision making in local government. Journal of Organizational Computing and Electronic Commerce 26(12), 64-79 (2016).

54. Lourenço R.P.: An analysis of open government portals: A perspective of transparency for accountability. Government Information Quarterly 32(3), 323-332 (2015).

55. Temiz S., Brown, T.: Open data project for e-government: Case study of Stockholm open data project. International Journal of Electronic Governance 9(1-2), 55-84 2017.

56. Kornberger M., Meyer R.E., Brandtner C., Höllerer M.A.: When Bureaucracy Meets the Crowd: Studying "Open Government" in the Vienna City Administration. Organization Studies 38(2), 179-200 (2017).

57. Donker F.W., Van Loenen B., Bregt A.K.: Open data and beyond. ISPRS International Journal of Geo-Information 5(4), 48 (2016).

58. Janssen, M., Charalabidis, Y., Zuiderwijk, A.: Benefits, Adoption Barriers and Myths of Open Data and Open Government. Information Systems Management 29(4), 258-268 (2012).

59. Graves A., Hendler J.: A study on the use of visualizations for Open Government Data. Information Polity 19(1-2), 73-91 (2014).

60. National Democratic Institute (NDI): Open Data is Only the Beginning: Civil Society Organisations as Public Data Analysts. (2013) https://www.ndi.org/sites/default/files/2013GhanaStanfordTransparencyPaper.pdf, last accessed 2017/09/20.

61. Meng, A.: Investigating the Roots of Open Data's Social Impact. JeDEM-eJournal of eDemocracy and open Government 6(1), 1-13 (2014).

62. Klaus, L. C. O.: Transforming armed forces through military transparency: open government challenges in a world of secrecy. Transforming Government: People, Process and Policy 10(1), 99-119 (2016).

63. Kamateri, E., Panopoulou, E., Tambouris, E., Tarabanis, K., Ojo, A., Lee, D., Price, D.: A comparative analysis of tools and technologies for policy making. In: Janssen, M., Wimmer, M.A., Deljoo (eds.) Policy Practice and Digital Science - Integrating Complex Systems, Social Simulation and Public Administration in Policy Research, pp. 125-156. Springer International Publishing, Heidelberg (2015).

64. Open Knowledge Definition (2017) http://opendefinition.org/okd/, last accessed 2017/09/20. 